\title{
O primeiro passo de uma revolução que vai mudar o Serviço Público no Brasil
}

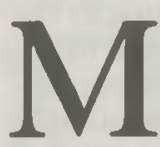
ais de setenta mil pessoas em todo o Brasil: este é o número de inscritos para o concurso de ingresso ao Curso de Políticas Públicas e Gestão Governamental, que efetiva a existência da ENAP - Escola Nacional de Administração Pública, voltada para a formação e o aperfeiçoamento do pessoal civil dos escalōes superiores da Administração Pública Federal e Autárquica.

A ENAP se propōe a preparar o gestor governamental para as mais altas decisões político-administrativas, conforme explica o Diretor Geral da ENAP, professor João Batista Cascudo Rodrigues.

Ex-diretor da Universidade Regional do Rio Grande do Norte, ex-diretor do Departamento de Capacitação em Recursos Humanos da Organização LatinoAmericana de Energia, com sede em Quito, no Equador, o professor João Batista Cascudo Rodrigues é pós-graduado em Administração Pública pela EBAP e ocupa, ainda, a presidência da Associação Latino-Americana de Administração Pública - ALAP.

\section{Participação}

Foram ao todo 70.775 os inscritos em todos os postos abertos no pais. Os ins critos passarão por três etapas de provas: as duas primeiras serão executadas pela Fundação CESGRANRIO. A terceira etapa, pela ENAP. A Etapa I, eliminatória e classificatória, a ser realizada nos locais de inscrição, consta de uma prova objetiva com 80 questões de múltipla escolha, envolvendo áreas de conhecimento das seguintes disciplinas: História Administrativa e Econômica do Brasil, Noçōes de
Administração, Noções de Economia, Noções de Ciência Política e Noções de Direito.

$\mathrm{Na}$ segunda Etapa, serão realizadas duas provas discursivas sobre questōes nacionais e internacionais, tratadas segundo as abordagens administrativa, econômica, política e juridica. Estas questões vão desde a discussão sobre sistema de governo, se presidencialismo ou parlamentarismo, ao federalismo no Brasil, e a temas como estatização ou privatização, sistema financeiro nacional, setor agrícola e desenvolvimento, questão energética, Ciência e Tecnologia, Desenvolvimento e Soberania Nacional, para citar apenas alguns.

Desta Etapa II faz parte também uma prova de Linguas, compreendendo uma Redação em Português sobre tema a ser desenvolvido, em igualdade de condições, por todos os candidatos, e uma prova de Língua estrangeira, Inglês ou Francês, envolvendo a compreensão de texto ou textos de publicação em livros, jornais ou revistas.

Na Etapa III, haverá uma entrevista e análise de currículo, de caráter classificatório, com a finalidade de verificar a adequação do perfil do candidato aos propósitos da ENAP. Os selecionados para esta etapa final passarão também por exame médico, de sanidade física e mental, de caráter eliminatório.

\section{Seleção}

O concurso para o primeiro curso da ENAP envolve critérios de eliminação e classificação. Serão, por exemplo, eliminados do concurso os candidatos que não alcancarem no total das questões objetivas, na Etapa I, pelo menos 30 por cento de acertos. Também será eliminado ocandidato que faltar a qualquer uma das provas ou etapas do Concurso. Para a Etapa II serão classificados até os 250 primeiros candidatos, oriundos da clientela externa, e até os 250 primeiros da clientela interna, excluindo-se, automaticamente, os demais candidatos.

Para a Etapa III, serão classificados os 200 candidatos: cem, oriundos da clientela externa e cem, da clientela interna. E finalmente a Etapa III selecionará 120 candidatos, 60 do grupo interno e 60 do grupo externo, que serão efetivamente os primeiros alunos do Curso de Políticas Públicas e Gestão Governamental.

\section{O Curso}

O curso, que deverá começar em agosto, terá a duração de um ano e meio, com horário integral e dedicação exclusiva, incluindo um estágio e dois períodos de quinze dias de férias. O estágio será realizado em Brasilia e/ou em qualquer outra cidade do país, com sua realização em organizações credenciadas pela ENAP.

Aos servidores da Administração Pública Federal direta e autárquica, integrantes da clientela interna, será garantida a manutenção de todos os direitos e vantagens dos cargos que ocupem, como se estivessem em efetivo exercício. Aos cursistas provenientes de outras unidades da $\mathrm{Fe}$ deraçāo serão oferecidas bolsas de estudo. Aos cursistas da clientela externa, residentes no Distrito Federal, também serão asseguradas bolsas de estudo. Os cursistas de clientela externa, que não tiverem sua remuneração mantida pelo órgão ou entidade de origem ou lotação, serão também beneficiados com bolsas de estudo. 


\section{ESPECIAL}

\section{CONCURSO DE SELECÃOÀ ENAP calendário}

\begin{tabular}{|c|c|c|}
\hline $\begin{array}{c}\text { PEAIODO } \\
21 / 12 / 87 \text { a } 04 / 03 / 88\end{array}$ & $\begin{array}{c}\text { HORÁRIO } \\
09: 00 \text { às } 17: 00\end{array}$ & EVENTO \\
\hline 05 a $07 / 04 / 88$ & $09: 00$ às $17: 00$ & $\begin{array}{l}\text { Entrega de cartōes aos candida- } \\
\text { tos e solicitaçōes de retificação }\end{array}$ \\
\hline $24 / 04 / 88$ & $08: 00$ às $12: 00$ & ETAPA I - Prova objetiva \\
\hline $04 / 05 / 88$ & & $\begin{array}{l}\text { Divulgação dos resultados e convo- } \\
\text { cação para a ETAPA II }\end{array}$ \\
\hline $08 / 05 / 88$ & $08: 00$ às $12: 00$ & $\begin{array}{l}\text { ETAPA II - la prova discursiva so } \\
\text { bre Questöes Nacionais e Internacio- } \\
\text { nais, segundo as abordagens adminis- } \\
\text { trativa e econômica. }\end{array}$ \\
\hline & $14: 00$ às $18: 00$ & $\begin{array}{l}\text { ETAPA II - Prova de Linguas: Por- } \\
\text { tuguês (Redação) e Francês ou In- } \\
\text { glës. }\end{array}$ \\
\hline $09 / 05 / 88$ & $08: 00$ às $12: 00$ & $\begin{array}{l}\text { ETAPA II } 2 \text { prova discursiva so- } \\
\text { bre Questões Nacionais e Internacio- } \\
\text { nais, segundo as abordagens politica } \\
\text { e jurídica. }\end{array}$ \\
\hline $14 / 05 / 88$ & & $\begin{array}{l}\text { Divulgação dos resultados da ETAPA } \\
\text { II. }\end{array}$ \\
\hline 16 a $18 / 05 / 88$ & - & $\begin{array}{l}\text { Prazo para pedido de revisão dos re- } \\
\text { sultados das provas da ETAPA II } \\
\text { (exceto prova de Línguas). }\end{array}$ \\
\hline $25 / 05 / 88$ & & $\begin{array}{l}\text { Resultados dos pedidos de revisão } \\
\text { da prova da ETAPA II e Divulgação } \\
\text { da lista de classificados para a ETA- } \\
\text { PA III e convocação para entrevistas } \\
\text { e exames médicos. }\end{array}$ \\
\hline $30 / 05 / 88$ a $14 / 06 / 88$ & & $\begin{array}{l}\text { Realização de entrevistas e exames } \\
\text { médicos (conforme convocação). }\end{array}$ \\
\hline $17 / 06 / 88$ & & Divulgação final dos resultados. \\
\hline
\end{tabular}

O professor João Batista Cascudo Rodrigues lembra que a capacitação de tecursos humanos - em caráter geral e permanente - constitui a pedra angular do sistema de carreiras, conforme as diretrizes fixadas pelo Decreto-lei n: 2.403 de 21 de dezembro de 1987. Esse é o principal passo para se eliminar a desvinculação entre capacitação e carreira, que se tem caracterizado como o aspecto disfuncional do Serviço Público Federal. Ao mesmo tempo, afirma, representa avanco considerável para a implementação da Reforma Administrativa, tal como foi preconizado no Decreto n: 91.309 , de 04 de junho de 1985, no qual se afirma: a "Reforma Administrativa contemplará, entre outros aspectos, o estabelecimento de sistema normativo destinado a valorizar os recursos humanos da Administração Pública, direta e indireta, estatuindo os cri. térios de seleção e administração por concurso público, bem como a capacitação e promoção, mediante cursos e estágios, objetivando que os cargos de direção e assessoramento superiores sejam exercidos pelos ocupantes dos quadros de carreira com base no aprimoramento profissional".

O Gestor Governamental a surgir do primeiro curso promovido pela ENAP, se incumbirá de pesquisar, planejar, organizar, orçamentar, recrutar, selecionar, treinar, prover e alocar recursos humanos, financeiros e materiais para toda e qualquer administração setorial em que ele se engaje, em função de suas qualificações teóricas e práticas, ao longo de sua história de vida.

\section{POSIÇÃO DOS INSCRITOS PARA O CONCURSO ENAP}

\begin{tabular}{|lc|}
\hline CIDADE & INSCRITOS \\
\hline São Paulo & 12.784 \\
Rio de Janeiro & 11.005 \\
Brasília & 7.580 \\
Belo Horizonte & 5.660 \\
Porto Alegre & 5.431 \\
Curitiba & 3.807 \\
Recife & 2.533 \\
Salvador & 2.397 \\
Vitória & 2.308 \\
Fortaleza & 2.119 \\
Goiânia & 1.677 \\
Belém & 1.591 \\
Florianópolis & 1.461 \\
Campo Grande & 1.450 \\
\hline
\end{tabular}

\begin{tabular}{|lc|}
\hline CIDADE & INSCRITOS \\
\hline Manaus & 1.435 \\
João Pessoa & 1.129 \\
Natal & 1.020 \\
Maceió & 949 \\
Teresina & 892 \\
São Luís & 845 \\
Cuiabá & 783 \\
Aracaju & 743 \\
Porto Velho & 522 \\
Macapá & 281 \\
Boa Vista & 205 \\
Rio Branco & 168 \\
\hline TOTAL & 70.775 \\
\hline
\end{tabular}

